\title{
Long-term denosumab treatment restores cortical bone loss and reduces fracture risk at the forearm and humerus: analyses from the FREEDOM Extension cross-over group
}

\author{
J.P. Bilezikian ${ }^{1}$ - C.J.F. Lin ${ }^{2}$ - J.P. Brown ${ }^{3}$ - A.T. Wang ${ }^{2} \cdot$ X. Yin ${ }^{2}$ - P.R. Ebeling ${ }^{4} \cdot$ A. Fahrleitner-Pammer ${ }^{5} \cdot$ E. Franek $^{6}$.

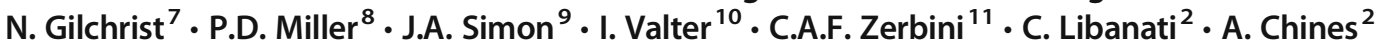

Received: 20 July 2018 / Accepted: 15 May 2019 / Published online: 14 June 2019

(C) The Author(s) 2019

\begin{abstract}
Summary Upper limb fractures (including wrist, forearm, and humerus) represent a significant burden among postmenopausal women with osteoporosis. Up to 7 years of treatment with denosumab resulted in an increase in bone mineral density and decrease in fractures in upper limb sites.

Introduction Upper limb (wrist, forearm, and humerus) fractures are a significant burden in osteoporosis, associated with significant morbidity and mortality. Denosumab, a monoclonal antibody against RANK ligand, increases bone mineral density (BMD) and decreases vertebral, nonvertebral, and hip fractures. Here, we evaluated the long-term effect of denosumab treatment on upper limb fracture risk and BMD.

Methods In the FREEDOM trial, subjects were randomized 1:1 to receive every-6-month denosumab 60 mg or placebo subcutaneously for 3 years, after which all subjects could receive denosumab for up to 7 years (Extension). Among placebo subjects who completed FREEDOM and enrolled in the Extension, wrist, forearm, humerus, and upper limb fracture rates and rate ratios between different time periods (FREEDOM years 1-3, Extension years 1-3, and Extension years 4-7) were computed. BMD at the ultradistal radius, 1/3 radius, and total radius was analyzed in a subset of subjects in a BMD substudy.

Results This analysis included 2207 subjects (116 in the BMD substudy). Fracture rates decreased over the 7-year Extension; fracture rate ratios between Extension years 4-7 (denosumab) and FREEDOM years 1-3 (placebo) reduced significantly for the wrist $(0.57)$, forearm $(0.57)$, humerus $(0.42)$, and upper limb $(0.52 ; p<0.05$ for all). Percentage increase in BMD from Extension baseline at the ultradistal radius, 1/3 radius, and total radius was significant by Extension year 7 ( $p<0.05$ for all).

Conclusions Long-term treatment with denosumab decreases upper limb fracture risk and increases forearm BMD, suggesting beneficial effects on both cortical and trabecular bone accruing over time.
\end{abstract}

Keywords BMD $\cdot$ Denosumab $\cdot$ Fractures $\cdot$ Osteoporosis

J.P. Bilezikian

jpb2@ cumc.columbia.edu

1 College of Physicians and Surgeons, Columbia University, New York, NY, USA

2 Amgen Inc., Thousand Oaks, CA, USA

3 CHU de Québec Research Centre and Laval University, Quebec City, QC, Canada

4 Department of Medicine, Monash University, Clayton, Australia
5 Medical University, Graz, Austria

6 Mossakowski Medical Research Center, Polish Academy of Sciences, Warsaw, Poland

7 The Burwood Hospital, Christchurch, New Zealand

8 Colorado Center for Bone Research, Golden, CO, USA

9 George Washington University, Washington, DC, USA

10 Center for Clinical and Basic Research, Tallinn, Estonia

11 Centro Paulista de Investigação Clinica, São Paulo, Brazil 


\section{Introduction}

Osteoporosis is characterized by reduced bone mineral density (BMD), increased microstructural deterioration, and, consequently, increased fracture risk. Worldwide, approximately 9 million new osteoporotic fractures occur per year, including 1.7 million fractures of the forearm, 1.6 million fractures of the hip, and 1.4 million clinical vertebral fractures [1]. Wrist fractures are the most common nonvertebral fractures in postmenopausal women with osteoporosis, particularly in elderly women [2-5]. Individuals with wrist fractures may experience chronic loss of function [6] and reduced quality of life [5]. Furthermore, wrist fractures are associated with significant morbidity [2-4] and may be associated with increased mortality, especially in men $[7,8]$. Forearm, wrist, and humerus fractures have also been shown to predict subsequent vertebral, hip, wrist, and forearm fractures [9-13].

Data on currently available therapies are limited with regard to treatment effects on wrist fractures and corresponding changes in BMD. Studies of alendronate have shown both significant [14] and nonsignificant [15] reductions in wrist fractures compared with placebo. Studies have also shown that bisphosphonates maintain reductions in BMD at the distal radius compared with baseline, especially at the $1 / 3$ radius, which is primarily cortical bone [16-19]. Studies of teriparatide have shown both significant decreases in wrist fractures [20] and significant reductions in wrist BMD [21] compared with placebo. Thus, previous reports of osteoporosis medications do not present a clear association between changes in BMD and fracture risk at the wrist.

In contrast to other antiresorptive therapies, denosumab-a fully human monoclonal antibody against RANK ligand (RANKL) - increases BMD at the 1/3 radius, as determined by dual-energy X-ray absorptiometry (DXA), more than alendronate not only in bisphosphonate treatment-naïve patients [22] but also in previously bisphosphonate-treated patients [23]. Denosumab also enhances BMD at the 1/3 radius more than zoledronic acid in patients previously treated with long-term alendronate [24]. In a phase 2 study, denosumab reduced bone resorption more rapidly and decreased cortical porosity more than alendronate [17].

While denosumab was not shown to reduce wrist fractures in the overall study population of the FREEDOM study [25, 26], improvements in bone mass, density, and strength [18] with denosumab treatment have been associated with reductions in wrist fractures among women at higher risk, defined as having a femoral neck BMD T-score $\leq-2.5$ [26]. Longterm experience with denosumab provides further support for the relationship between increases in BMD and reductions in nonvertebral fracture risk $[27,28]$.

No study has assessed the effect of treatment on long-term (>3 years) forearm BMD changes and the risk of upper limb fractures (i.e., wrist, forearm, and humerus). With this objective, we evaluated the long-term effects of denosumab treatment on changes in forearm BMD by DXA and their relationship with fracture incidence at three different upper limb sites. We used data from the cross-over group of subjects from the FREEDOM Extension trial, who received 3 years of placebo followed by up to 7 years of denosumab. The results provide further evidence for the beneficial effects of denosumab at both cortical and trabecular compartments of the bone, leading to reductions in the risk of upper limb fractures.

\section{Methods}

\section{Study design}

The 3-year FREEDOM trial (NCT00089791) and its 7 year Extension (NCT00523341) have been described previously $[25,28]$. Briefly, FREEDOM was a phase 3, randomized, double-blind, placebo-controlled study to evaluate the efficacy and safety of denosumab in postmenopausal women with osteoporosis. Subjects were randomized to receive either placebo or denosumab $60 \mathrm{mg}$ subcutaneously (SC) every 6 months (Q6M) for 3 years. Subjects were instructed to take calcium $(\geq 1 \mathrm{~g})$ and vitamin $\mathrm{D}(\geq 400 \mathrm{IU})$ daily. Subjects who completed the FREEDOM trial, did not discontinue investigational product, and did not miss $>1$ dose of investigational product were eligible to enter a 7-year Extension trial. During the Extension, all subjects were to receive open-label denosumab $60 \mathrm{mg} \mathrm{SC} \mathrm{Q6M,}$ with daily calcium and vitamin D.

This analysis evaluated subjects who were randomized to receive placebo for 3 years in the FREEDOM, entered the Extension study, and received denosumab for up to 7 years (i.e., the cross-over group). The cross-over group was chosen because it provided fracture rates during the placebo period, which was used for within-group comparisons. Fracture rates at the wrist, forearm, humerus, and all upper limb fractures together were assessed in all subjects from the cross-over group. A subset of subjects from the cross-over group also participated in a BMD substudy, in which forearm BMD was measured. This substudy was prespecified in both the FREEDOM and Extension trial protocols.

\section{Study population}

Subjects who were randomized to placebo in the FREEDOM and received up to 7 years of denosumab in the Extension were included in this analysis. Subject inclusion and exclusion criteria have been described previously [28]. Women between the age of 60 and 90 years with a lumbar spine or total hip BMD T-score $\leq-2.5$ at either site but $>-4.0$ at both sites were eligible for the FREEDOM trial. 


\section{Outcome measures}

BMD assessments were performed by DXA. DXA measurements were obtained by Lunar or Hologic instruments (GE Healthcare, Chicago, IL, or Hologic Inc., Marlborough, MA, respectively). All DXA scans were analyzed centrally by Synarc (Portland, OR) in a blinded fashion. During the 10year course of FREEDOM and its Extension, the central laboratory made appropriate adjustments upon each change in software to ensure consistency of BMD results. Ultradistal radius, $1 / 3$ radius, and total radius DXA measurements were recorded for a subset of subjects at FREEDOM baseline, during FREEDOM (years 1-3), and during FREEDOM Extension (years 1-3, 5, and 7). Wrist, forearm, humerus, and upper limb (combined wrist, forearm, and humerus) fracture rates were confirmed by a central imaging vendor for all subjects through year 3 in the FREEDOM study and through year 7 of FREEDOM Extension. Fractures of interest by site were defined in the following manner: wrist fractures included fractures at the distal radius and distal ulna; forearm fractures included fractures at the proximal radius/ulna, shaft radius/ ulna, and distal radius/ulna; humerus fractures included fractures at the proximal humerus, shaft humerus, and distal humerus; and upper limb fractures included fractures at the forearm and humerus. Traumatic and pathologic fractures were excluded. Changes in BMD and fracture rates were evaluated in three time periods to allow for within-group comparisonsFREEDOM years 1-3, Extension years 1-3, and Extension years 4-7-to evaluate patients after they received 3 years of placebo, 3 years of denosumab, and 4 additional years of denosumab, respectively. Fracture rates were compared between either the first 3 years on denosumab or the subsequent last 4 years on denosumab with the first 3 years on placebo to assess the effect of denosumab treatment on fracture rates. To adjust for various lengths of follow-up, fracture rates were expressed as per 100 subject-years. Rate ratios were used for within-group comparison between placebo and denosumab treatment periods. Fracture rates and changes in BMD are also reported for the long-term group (i.e., subjects randomized to receive denosumab during FREEDOM, entered the Extension, and received denosumab for up to an additional 7 years), to compare with those observed in the cross-over group during the same period of denosumab treatment in the Extension (i.e., the first 3 years and following 4 years of denosumab treatment).

\section{Statistical analyses}

Baseline demographic and disease characteristic values were summarized using descriptive statistics. The percentage change from FREEDOM baseline and Extension baseline in BMD at the ultradistal radius, 1/3 radius, and total radius by visit (during the FREEDOM and its Extension) was analyzed using a repeated-measures mixed-effects model with an unstructured within-subject variance-covariance structure. The model included treatment, visit (categorical), baseline BMD value, age stratification variable, densitometry machine type, treatment-by-visit interaction, and BMD baseline value-bydensitometry machine-type interaction. Least squares mean estimates of the percentage change from baseline in BMD within each treatment group and by visit, and the corresponding two-sided $95 \%$ confidence intervals (CIs), were estimated. Wrist, forearm, humerus, and upper limb fracture rates (per 100 subject-years) were computed, and the rate ratios (comparing FREEDOM Extension years 1-3 or 4-7 with placebo FREEDOM years $1-3$ and comparing FREEDOM Extension years 4-7 with FREEDOM Extension years 1-3) and the corresponding 95\% CIs were estimated by generalized estimating equation method in a Poisson regression model. All $p$ values were not adjusted for multiplicity.

\section{Results}

\section{Subjects}

Of the 3906 subjects randomized to placebo in FREEDOM, 2207 entered the FREEDOM Extension. The FREEDOM BMD substudy enrolled 441 subjects (209 placebo and 232 denosumab) at FREEDOM baseline; results from the FREEDOM substudy have previously been published [29]. Among the 209 placebo subjects in the FREEDOM BMD substudy, 116 enrolled in the Extension and had at least one $1 / 3$ radius BMD measurement at baseline or postbaseline in the Extension. Baseline characteristics for FREEDOM and FREEDOM Extension subjects who entered FREEDOM Extension and those who participated in the BMD substudy are shown in Table 1. At the beginning of the FREEDOM trial, subjects had a mean age of 72 years, $28 \%$ of the subjects were over the age of 75 years, and $22 \%$ had a prevalent vertebral fracture. Within the BMD substudy at FREEDOM baseline, mean age was 72 years, $34 \%$ of the subjects were over the age of 75 years, $21 \%$ had a prevalent vertebral fracture, and mean (standard deviation) BMD T-score was -2.5 at the $1 / 3$ radius and -2.5 at the ultradistal radius.

Baseline characteristics were similar between the overall population and the substudy population. Between the FREEDOM and Extension trials, baseline characteristics were similar except that subjects were 3 years older and had 3 years longer since menopause; the percentage of subjects aged over 75 years and those with prevalent vertebral and nonvertebral fractures was, as expected, greater, and $\mathrm{T}$-scores (total hip, 1/3 radius, and ultradistal radius) were lower. 
Table 1 FREEDOM and Extension baseline characteristics

\begin{tabular}{|c|c|c|c|c|}
\hline \multirow[t]{3}{*}{ Characteristic } & \multicolumn{4}{|c|}{ Cross-over Extension subjects } \\
\hline & \multicolumn{2}{|c|}{ FREEDOM baseline } & \multicolumn{2}{|c|}{ Extension baseline } \\
\hline & $\begin{array}{l}\text { Overall } \\
N=2207\end{array}$ & $\begin{array}{l}\text { Substudy } \\
N 1=116\end{array}$ & $\begin{array}{l}\text { Overall } \\
N=2207\end{array}$ & $\begin{array}{l}\text { Substudy } \\
N 1=116\end{array}$ \\
\hline Age (years) & $71.8(5.1)$ & $72.2(5.2)$ & $74.8(5.1)$ & $75.2(5.2)$ \\
\hline \multicolumn{5}{|l|}{ Age groups (\%) } \\
\hline$\geq 65$ years & 93.7 & 94.0 & 97.4 & 96.6 \\
\hline$\geq 75$ years & 28.3 & 33.6 & 52.2 & 56.0 \\
\hline Time since menopause (years) & $23.7(7.4)$ & $24.3(8.4)$ & $26.7(7.4)$ & $27.3(8.4)$ \\
\hline BMI $\left(\mathrm{kg} / \mathrm{m}^{2}\right)$ & $26.0(4.1)$ & $24.9(4.3)$ & $25.9(4.2)$ & $25.0(4.4)$ \\
\hline Height $(\mathrm{cm})$ & $157.0(6.9)$ & $157.7(6.7)$ & $157.0(6.9)$ & $157.7(6.7)$ \\
\hline Weight (kg) & $64.0(10.3)$ & $62.0(10.5)$ & $63.7(10.7)$ & $62.3(10.9)$ \\
\hline Prevalent vertebral fracture $(\%)$ & 22.0 & 20.7 & 25.0 & 24.1 \\
\hline $\begin{array}{l}\text { Prevalent nonvertebral fracture at age } \\
\geq 55 \text { years }(\%)\end{array}$ & 29.5 & 27.6 & 34.2 & 31.0 \\
\hline Lumbar spine BMD T-score & $-2.84(0.68)$ & $-2.81(0.61)$ & $-2.81(0.75)$ & $-2.80(0.66)$ \\
\hline Total hip BMD T-score & $-1.85(0.79)$ & $-1.85(0.64)$ & $-1.93(0.80)$ & $-1.92(0.63)$ \\
\hline $1 / 3$ radius BMD T-score ${ }^{a}$ & N/A & $-2.53(1.18)$ & N/A & $-2.66(1.13)$ \\
\hline Ultradistal radius BMD T-score ${ }^{\mathrm{a}}$ & N/A & $-2.47(1.02)$ & N/A & $-2.65(1.04)$ \\
\hline sCTx, ${ }^{b}$ ng/mL, median (Q1, Q3) & $\begin{array}{l}0.56(0.42 \\
0.66)\end{array}$ & $\begin{array}{c}0.53(0.37 \\
0.61)\end{array}$ & $\begin{array}{l}0.57(0.43 \\
0.73)\end{array}$ & $\begin{array}{c}0.45(0.36 \\
0.60)\end{array}$ \\
\hline $\mathrm{P} 1 \mathrm{NP},{ }^{\mathrm{b}} \mu \mathrm{g} / \mathrm{L}$, median $(\mathrm{Q} 1, \mathrm{Q} 3)$ & $\begin{array}{c}55.81(42.52 \\
65.60)\end{array}$ & $\begin{array}{c}47.02(43.00 \\
67.88)\end{array}$ & $\begin{array}{l}48.80(35.04 \\
67.58)\end{array}$ & $\begin{array}{c}50.65(36.49, \\
59.99)\end{array}$ \\
\hline Serum 25 -hyrdoxyvitamin $\mathrm{D}^{\mathrm{c}} \mathrm{ng} / \mathrm{mL}$ & $24.29(34.78)$ & $22.34(8.11)$ & N/A & N/A \\
\hline
\end{tabular}

$N=2207$ was defined as the number of subjects randomized to placebo in the FREEDOM and enrolled in the Extension

$N 1=116$ was defined as the number of subjects enrolled in the Extension DXA substudy with the FREEDOM baseline and at least one postbaseline 1/3 radius BMD measurement in the FREEDOM or the Extension

Data are mean (standard deviation) unless otherwise noted

$B M D$, bone mineral density; $B M I$, body mass index; $B T M$, bone turnover marker; $D X A$, dual-energy x-ray absorptiometry; $N / A$, not applicable; $P 1 N P$, procollagen type $1 \mathrm{~N}$-terminal propeptide; $Q$, quartile; $s C T x$, serum C-telopeptide of type 1 collagen

${ }^{\text {a }}$ BMD measurements at the $1 / 3$ radius and ultradistal radius were performed in a subset of subjects enrolled in the DXA substudy

${ }^{\mathrm{b}}$ BTM subsets include subjects who enrolled in the BTM substudy

${ }^{\mathrm{c}}$ Serum 25-hydroxyvitamin D was only assessed in the FREEDOM

\section{Upper limb fractures}

The overall rate of upper limb fractures, including the wrist, forearm, and humerus, decreased over the 7-year course of treatment with denosumab (Fig. 1).

The incidence of wrist fractures was 1.02 per 100 subjectyears during FREEDOM years 1-3 (during which all subjects received placebo) and 0.96 during Extension years 1-3 (during which all subjects received denosumab; rate ratio not significant), and decreased to 0.58 during Extension years 4-7 (rate ratio $(95 \% \mathrm{CI})=0.57(0.38-0.86) ; p=0.0077$, Extension years 4-7 vs FREEDOM years 1-3; Fig. 1a).

Within these same periods, the rate of forearm fractures was 1.14 per 100 subject-years during FREEDOM years 1-
3 and 1.03 during Extension years 1-3 (rate ratio not significant), and decreased to 0.65 during Extension years 4-7 (rate ratio $(95 \% \mathrm{CI})=0.57(0.39-0.84) ; p=0.0042$, Extension years 4-7 vs FREEDOM years 1-3; Fig. 1b).

The incidence of humerus fractures decreased from 0.44 per 100 subject-years during FREEDOM years $1-3$ to 0.20 during Extension years 1-3 (rate ratio $(95 \% \mathrm{CI})=0.45(0.23-$ 0.89 ); $p=0.0214$, Extension years $1-3$ vs FREEDOM years 1-3; Fig. 1c), and to 0.18 during Extension years 4-7 (rate ratio $(95 \% \mathrm{CI})=0.42(0.21-0.83) ; p=0.013$, Extension years 4-7 vs FREEDOM years $1-3$; Fig. 1c).

The fracture rate of the entire upper limb per 100 subject-years was 1.56 during FREEDOM years $1-3$ and 1.23 during Extension years 1-3 (rate ratio not 
a
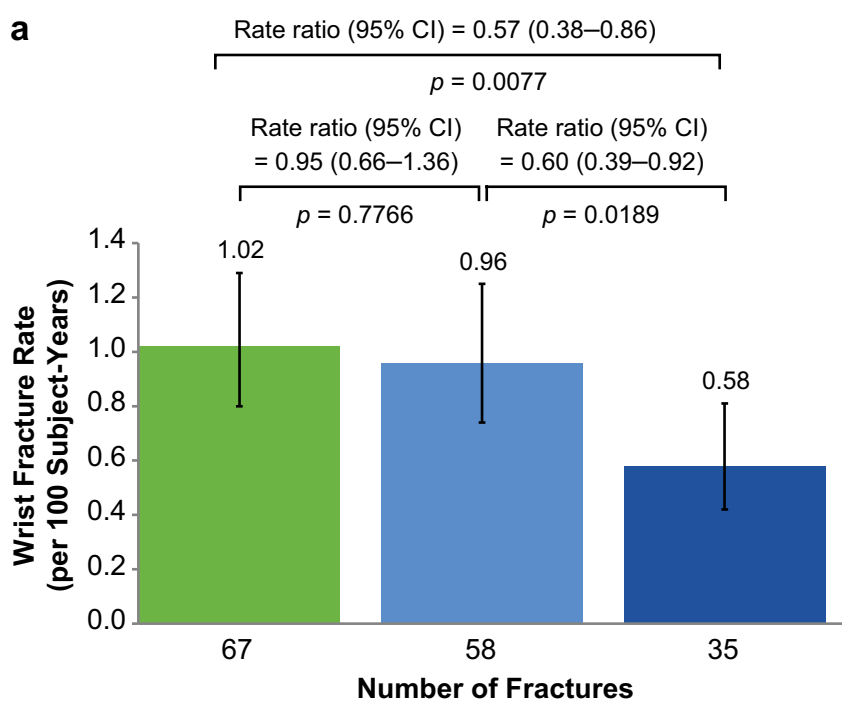

C
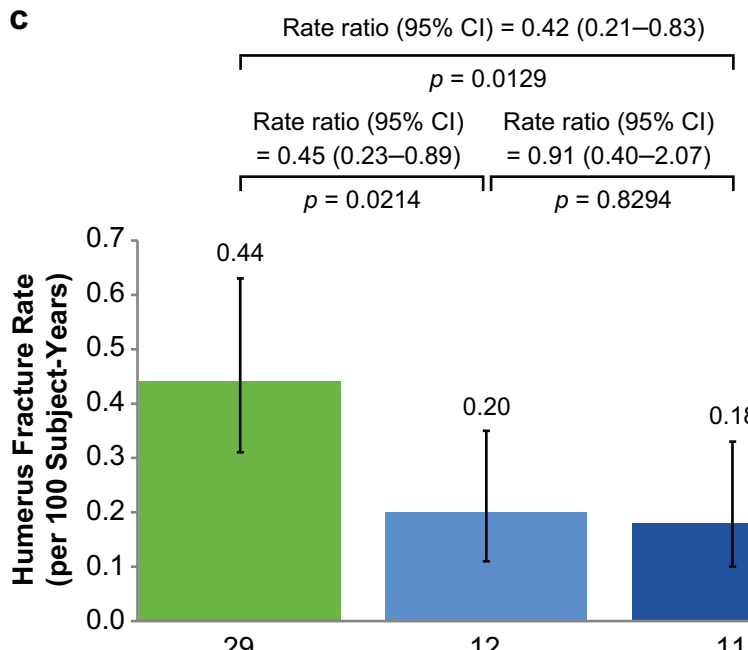

29



12

Number of Fractures b



Rate ratio $(95 \% \mathrm{Cl}) \quad$ Rate ratio $(95 \% \mathrm{Cl})$

$\stackrel{=0.91(0.64-1.28)}{r_{p=0.5740}} \underset{p=0.63(0.42-0.94)}{=0.0239}$



75

62

39

Number of Fractures

d $\frac{\text { Rate ratio }(95 \% \mathrm{Cl})=0.52(0.37-0.72)}{p=0.0001}$

Rate ratio $(95 \% \mathrm{Cl}) \quad$ Rate ratio $(95 \% \mathrm{Cl})$ $\sqrt{=0.79(0.58-1.06)}=0.66(0.46-0.95)$

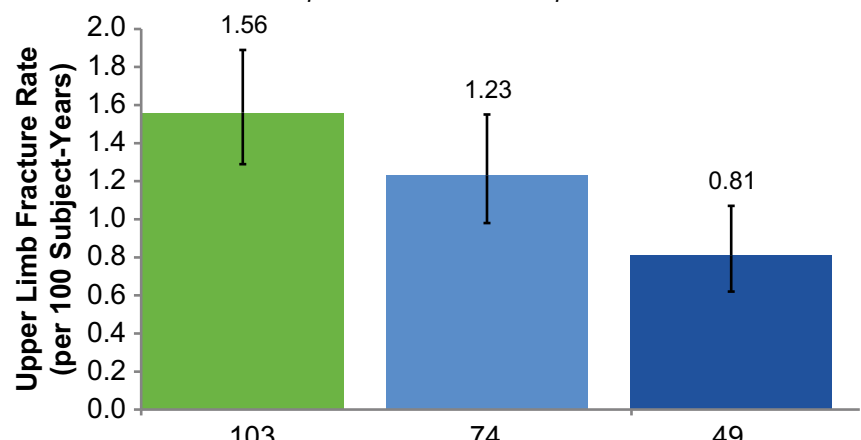

Number of Fractures

- Placebo Denosumab Extension (Year 1-3) Denosumab Extension (Year 4-7)

Fig. 1 Wrist, forearm, humerus, and all upper limb fracture rate. Fracture incidence $(95 \% \mathrm{CI})$ per 100 subject-years at the a wrist, b forearm, c humerus, and $\mathbf{d}$ all upper limb. 95\% CIs were estimated by generalized estimating equation (GEE) method in a Poisson regression model. All $p$ values were not adjusted for multiplicity. CI, confidence interval

(0.38-0.75), $0.06(0.02-0.17)$, and $0.60(0.44-0.82)$, respectively.

\section{Bone mineral density}

At the end of FREEDOM year 3, when all subjects had received placebo, BMD at the ultradistal radius, $1 / 3$ radius, and total radius decreased from baseline by $2.1 \%, 1.2 \%$, and $1.9 \%$, respectively (Table 2 and Fig. 2). During the 7-year Extension study, when all subjects received denosumab, BMD increased significantly from Extension baseline at all sites and all time points observed - ultradistal radius, $1 / 3$ radius, and total radius - with the exception of the $1 / 3$ radius at year $1(p=$ $0.2308)$ and year $2(p=0.5141$; Table 2$)$, restoring the BMD CI) per 100 subject-years were $0.49(0.34-0.69), 0.54$ 
Table 2 Percentage change in bone mineral density from the FREEDOM and Extension baselines

\begin{tabular}{|c|c|c|c|c|c|c|}
\hline \multirow[t]{2}{*}{ Year } & \multicolumn{3}{|c|}{ From FREEDOM baseline } & \multicolumn{3}{|c|}{ From Extension baseline } \\
\hline & $n$ & LS mean $(95 \% \mathrm{CI})$ & $p$ value & $n$ & LS mean $(95 \% \mathrm{CI})$ & $p$ value \\
\hline \multicolumn{7}{|c|}{ a. Ultradistal radius } \\
\hline \multicolumn{7}{|c|}{ FREEDOM (placebo) } \\
\hline Year 1 & 113 & $-0.4(-1.3,0.6)$ & 0.4457 & $\mathrm{~N} / \mathrm{A}$ & N/A & $\mathrm{N} / \mathrm{A}$ \\
\hline Year 2 & 109 & $-0.9(-1.9,0.1)$ & 0.0633 & N/A & N/A & N/A \\
\hline Year 3 & 111 & $-2.1(-3.5,-0.8)$ & 0.0014 & N/A & N/A & N/A \\
\hline \multicolumn{7}{|c|}{ Extension (denosumab) } \\
\hline Year 1 & 113 & $0.6(-1.1,2.4)$ & 0.4541 & 114 & $2.9(1.2,4.5)$ & 0.0008 \\
\hline Year 2 & 107 & $0.6(-1.3,2.4)$ & 0.5371 & 108 & $2.8(1.1,4.5)$ & 0.0015 \\
\hline Year 3 & 73 & $1.2(-0.6,3.0)$ & 0.2055 & 73 & $3.5(1.7,5.3)$ & 0.0001 \\
\hline Year 5 & 59 & $2.2(0.4,4.0)$ & 0.0195 & 59 & $4.5(2.8,6.2)$ & $<0.0001$ \\
\hline Year 7 & 39 & $0.7(-1.3,2.7)$ & 0.4963 & 39 & $3.2(1.2,5.3)$ & 0.0025 \\
\hline \multicolumn{7}{|c|}{ b. $1 / 3$ radius } \\
\hline \multicolumn{7}{|c|}{ FREEDOM (placebo) } \\
\hline Year 1 & 113 & $-0.1(-0.6,0.5)$ & 0.7807 & N/A & N/A & N/A \\
\hline Year 2 & 109 & $-0.7(-1.42,-0.1)$ & 0.0275 & N/A & N/A & N/A \\
\hline Year 3 & 111 & $-1.2(-1.9,-0.4)$ & 0.0024 & N/A & N/A & N/A \\
\hline \multicolumn{7}{|c|}{ Extension (denosumab) } \\
\hline Year 1 & 113 & $-1.0(-1.7,-0.3)$ & 0.0072 & 114 & $0.3(-0.2,0.9)$ & 0.2308 \\
\hline Year 2 & 107 & $-1.2(-1.9,-0.4)$ & 0.0033 & 108 & $0.2(-0.4,0.9)$ & 0.5141 \\
\hline Year 3 & 73 & $-0.2(-1.1,0.7)$ & 0.6519 & 73 & $1.3(0.5,2.0)$ & 0.0011 \\
\hline Year 5 & 59 & $0.3(-0.7,1.3)$ & 0.5451 & 59 & $1.8(0.9,2.7)$ & 0.0001 \\
\hline Year 7 & 39 & $0.6(-0.8,2.1)$ & 0.3974 & 39 & $2.2(0.9,3.6)$ & 0.0017 \\
\hline \multicolumn{7}{|c|}{ c. Total radius } \\
\hline \multicolumn{7}{|c|}{ FREEDOM (placebo) } \\
\hline Year 1 & 113 & $-0.4(-1.0,0.2)$ & 0.1534 & N/A & N/A & N/A \\
\hline Year 2 & 109 & $-1.2(-1.8,-0.5)$ & 0.0003 & N/A & N/A & N/A \\
\hline Year 3 & 111 & $-1.9(-2.6,-1.2)$ & $<0.0001$ & N/A & N/A & N/A \\
\hline \multicolumn{7}{|c|}{ Extension (denosumab) } \\
\hline Year 1 & 113 & $-1.0(-1.7,-0.2)$ & 0.0139 & 114 & $1.2(0.7,1.8)$ & $<0.0001$ \\
\hline Year 2 & 107 & $-1.2(-2.0,-0.3)$ & 0.0076 & 108 & $1.1(0.4,1.7)$ & 0.0012 \\
\hline Year 3 & 73 & $-0.3(-1.2,0.5)$ & 0.4608 & 73 & $2.0(1.3,2.8)$ & $<0.0001$ \\
\hline Year 5 & 59 & $0.1(-0.8,1.1)$ & 0.7928 & 59 & $2.5(1.7,3.4)$ & $<0.0001$ \\
\hline Year 7 & 39 & $-0.4(-1.7,0.9)$ & 0.5693 & 39 & $2.1(0.9,3.3)$ & 0.0009 \\
\hline
\end{tabular}

$n=$ number of subjects with observed data

Based on a repeated-measures mixed-effects model adjusted for treatment, age stratification variable, visit, baseline value, machine type, treatment-by-visit interaction, and baseline value-by-densitometry machine-type interaction

$C I$, confidence interval; $L S$, least squares; $N / A$, not applicable that was lost during the FREEDOM study when patients received placebo. The time course of denosumab-associated change in total radius BMD from baseline mimicked that at the $1 / 3$ radius site. The increases in BMD were more pronounced at the ultradistal radius than at either the $1 / 3$ radius or total radius. For comparison, in the long-term group, BMD was maintained or continued to increase with 4 additional years of denosumab treatment (i.e., during Extension years 4-7 or years 7-10 of denosumab treatment) (data not shown).

\section{Discussion}

The objective of this study was to evaluate the long-term treatment effect of denosumab on fracture risk of the upper limb and the associated changes in BMD at the forearm, including ultradistal radius, 1/3 radius, and total radius sites. During FREEDOM Extension, long-term denosumab treatment significantly decreased the risk of upper limb fractures, including wrist, forearm, and humerus, which was associated 
Fig. 2 Percentage change in ultradistal radius, $1 / 3$ radius, and total radius BMD from

FREEDOM baseline. $n=$ number of subjects with observed data. Percentage change based on a repeated-measures mixed-effects model adjusted for treatment, age stratification variable, visit, baseline BMD value, machine type, treatment-by-visit interaction, and baseline value-by-machine-type interaction. $* p<0.05$ vs FREEDOM baseline. BMD, bone mineral density; BTM, bone turnover marker; $\mathrm{CI}$, confidence interval; DXA, dual-energy x-ray absorptiometry; Q6M, every 6 months


with a complete reversal of bone loss observed during the first 3 years of FREEDOM, when these patients received only calcium and vitamin D supplementation.

Upper limb fractures account for about one-third of all osteoporosis-related fractures in the elderly and are associated with significant morbidity and mortality $[4,8]$ and loss of quality of life [5]. The present study is the first to examine the long-term effect of osteoporosis treatment on upper limb fractures, indicating that 7 years of denosumab treatment was associated with a significant $48 \%$ reduction in the risk of all upper limb fractures and a $43 \%, 43 \%$, and $58 \%$ reduction in risk of forearm, wrist, and humerus fractures, respectively, compared with placebo treatment during FREEDOM. Fracture risk reduction with denosumab, however, was not evident during the first 3 years of treatment during the Extension but rather during the last 4 years of treatment, with the exception of the humerus, where a 55\% reduction was observed within the first 3 years of denosumab treatment and sustained through 7 years of treatment. It is unclear why the humerus appears to respond earlier to denosumab treatment than the wrist and forearm. While findings from the FREEDOM study demonstrated a significant reduction in 
nonvertebral fractures with 3 years of denosumab treatment compared with placebo [25], this current longitudinal analysis suggests that reduction of upper limb fractures may require more than 3 years of therapy because cortical bone is relatively slow to react to an antiresorptive, particularly at a relatively low load site with little - if any — modeling-based bone formation [30]. It should be mentioned that by the end of the 7-year Extension period, patients were older and, thus, at higher fracture risk compared with the first 3 years of FREEDOM, potentially underestimating the fracture risk reduction observed with denosumab treatment in this longitudinal study without a parallel comparator arm. Our findings indicate that denosumab effectively reduces fractures in the upper limb, including the wrist and humerus, with important clinical implications. Recent recommendations from the National Bone Health Alliance expanded the diagnosis of osteoporosis to include fractures at the proximal humerus and, in some cases, distal forearm in patients with osteopenic BMD [31].

Although some studies have shown a reduction in wrist fractures with alendronate treatment $[14,32]$, others have shown neither a reduction in wrist fractures nor an increase in wrist BMD $[15,19]$. A Cochrane review showed an overall relative risk reduction of about $50 \%$ for wrist fractures with alendronate treatment [33]. No studies have reported the effect of antiresorptive agents on other upper limb fractures.

Among available osteoporosis therapies, reduction in vertebral fracture risk is a consistent finding that becomes evident relatively early in the course of treatment. In addition, the size of the treatment effect on vertebral fractures is greater than that on nonvertebral fractures. Reductions in nonvertebral fractures, including at the upper extremities, are less pronounced with antiresorptive therapies and appear to require a longer treatment duration. Treatment with denosumab results in reductions in vertebral fractures after 1 year, whereas reductions in nonvertebral fractures occur after 3 years. Longer term denosumab treatment beyond 3 years has been shown to be associated with further reductions in nonvertebral fractures [27]. This long-term, beneficial treatment effect is thought to be derived not only from the increase in bone mass but also from reductions in cortical porosity and increases in cortical thickness and strength documented at nonvertebral sites, including the distal radius, tibia, and hip [17, 34].

In contrast, longer treatment with alendronate for up to 10 years [35] or zoledronic acid for up to 9 years [36] was not associated with further reductions in nonvertebral fractures compared with the first 3 years of each respective treatment. This may be explained by the differing effects of denosumab and alendronate on cortical bone [17], as well as the differing effects on femoral neck BMD that plateaus after 2-3 years of treatment with bisphosphonates. To inhibit resorption, bisphosphonates must first be adsorbed to hydroxyapatite bone mineral surfaces - more abundantly expressed on trabecular bone than cortical—underneath the osteoclasts, and then later be taken up by osteoclasts during resorption [16]. Thus, some resorption must occur before bisphosphonates can inhibit osteoclastic activity. Furthermore, bisphosphonates do not prevent osteoclastogenesis. By contrast, denosumab, a fully human monoclonal antibody against RANKL that does not require binding to bone mineral surfaces, reduces osteoclastogenesis and bone resorption more completely and rapidly than bisphosphonates and may penetrate deeper into cortical bone [16]. These differences in mechanisms of action may confer larger effects of denosumab compared with alendronate on cortical bone [17].

The strength of this study is that it reports long-term, 10-year changes in BMD at three sites of interest at the radius. The fracture risk reduction calculations were based on a large sample size, i.e., all subjects randomized to placebo in the FREEDOM trial who entered the Extension. In addition, the 7 years of denosumab treatment in the cross-over group could be compared with the first 7 years of denosumab treatment in the long-term group; those findings show similar outcomes, demonstrating that longer term denosumab treatment (beyond 3 years) further decreases fracture risk. The limitation of this study is the relatively small number of subjects who participated in the BMD substudy; however, as baseline characteristics were similar between the subjects enrolled in the overall cross-over group and in the BMD substudy, the subjects investigated appear to be representative of the overall study population. DXA does not measure humeral BMD, so it is not possible to associate reductions in humerus fracture rates with increases in BMD at that skeletal site. This study is also limited by the open-label, single-arm design of the Extension trial and the lack of a placebo group.

In conclusion, compared with the initial 3 years of treatment with calcium and vitamin D supplements during the FREEDOM trial, 7 years of denosumab treatment decreased the incidence of upper limb fractures, including those at the wrist, humerus, and forearm. The beneficial effect of denosumab treatment on fractures was associated with significant increases in BMD over the 7year course of therapy compared with Extension baseline and complete reversal of the bone loss observed during the first 3 years of the FREEDOM trial. This study also suggests that for some nonvertebral skeletal sites, such as the upper limb, a treatment duration of more than 3 years results in significant and clinically meaningful treatment effect. Considering the reversibility of denosumab, as well as its long-term safety and proven efficacy, continued treatment with a drug holiday is a very important consideration. These findings support the treatment benefits of longterm therapy with potent antiresorptive agents, such as denosumab, and their importance in enabling a patient to maintain one's independence, activity level, and overall quality of life.

Acknowledgments The authors would like to thank Jessica, Ma, $\mathrm{PhD}$ (Amgen Inc.), for medical writing support.

Funding This study was funded by Amgen Inc. 
Data availability Qualified researchers may request data from Amgen clinical studies. Complete details are available at the following: https:// wwwext.amgen.com/science/clinical-trials/clinical-data-transparencypractices/

\section{Compliance with ethical standards}

Ethical approval All procedures performed in studies involving human participants were in accordance with the ethical standards of the institutional and/or national research committee and with the 1964 Helsinki declaration and its later amendments or comparable ethical standards.

Conflict of interest JP Bilezikian has received research grants from the National Institutes of Health and has received consulting fees from Amgen, Radius, Ultragenyx, Alexion, and Shire. CJF Lin is a former employee and stockholder of Amgen Inc. JP Brown has received research grants from Amgen Inc., Eli Lilly, and Mereo BioPharma; received consulting fees from Amgen Inc., Eli Lilly, and Merck; and served on the speakers' bureau for Amgen Inc. and Eli Lilly. AT Wang, X Yin, and A Chines are employees and stockholders of Amgen Inc. P Ebeling has received research grants from Amgen Inc., Eli Lilly, Novartis, and Alexion, and has received consulting fees from Amgen Inc., Eli Lilly, Alexion, and Gilead. A Fahrleitner-Pammer has received consulting fees from Eli Lilly and has served on the speakers' bureau for Alexion, Amgen Inc., Eli Lilly, and Stada. E Franek has served on the speakers' bureau for Amgen Inc., Eli Lilly, and MSD. N Gilchrist has received research grants from Amgen Inc. PD Miller has received research grants from Amgen Inc., Alexion, Radius Pharma, and Regeneron. JA Simon has received research grants from AbbVie Inc., Allergan Plc, Agile Therapeutics, Bayer Healthcare LLC., Dornier MedTech, Endoceutics Inc., GTx, Inc., Ipsen, Myovant Sciences, New England Research Institute Inc., ObsEva SA, Palatin Technologies, Symbio Research Inc., TherapeuticsMD, and Tissue Genesis; has ownership in James A. Simon, MD, PC; has received consulting fees from AbbVie Inc., Allergan Plc, AMAG Pharmaceuticals Inc., Amgen Inc., Ascend Therapeutics, Bayer HealthCare Pharmaceuticals Inc., CEEK Enterprises LLC., Covance Inc., Millendo Therapeutics Inc., Mitsubishi Tanabe Pharma Development America Inc., ObsEva SA, Radius Health Inc., Sanofi S.A., Sebela Pharmaceuticals Inc., Shionogi Inc., Symbiotec Pharmalab, TherapeuticsMD, and Valeant Pharmaceuticals; has served on the speakers' bureau for AMAG Pharmaceuticals Inc., Duchesnay USA, Novo Nordisk, Shionogi Inc., and Valeant Pharmaceuticals; and is a stockholder in Sermonix Pharmaceuticals. I Valter has nothing to disclose. CAF Zerbini has received research grants from Pfizer, Amgen Inc., Sanofi, MSD, Novartis, and Lilly, and has served on the speakers' bureau for Pfizer, Lilly, and Sanofi. C Libanati is an employee and stockholder of UCB Pharma.

Open Access This article is distributed under the terms of the Creative Commons Attribution-NonCommercial 4.0 International License (http:// creativecommons.org/licenses/by-nc/4.0/), which permits any noncommercial use, distribution, and reproduction in any medium, provided you give appropriate credit to the original author(s) and the source, provide a link to the Creative Commons license, and indicate if changes were made.

\section{References}

1. Johnell O, Kanis JA (2006) An estimate of the worldwide prevalence and disability associated with osteoporotic fractures. Osteoporos Int 17(12):1726-1733. https://doi.org/10.1007/ s00198-006-0172-4
2. Barrett-Connor E, Siris ES, Wehren LE, Miller PD, Abbott TA, Berger ML, Santora AC, Sherwood LM (2005) Osteoporosis and fracture risk in women of different ethnic groups. J Bone Miner Res 20(2):185-194. https://doi.org/10.1359/JBMR.041007

3. Siris ES, Chen YT, Abbott TA, Barrett-Connor E, Miller PD, Wehren LE, Berger ML (2004) Bone mineral density thresholds for pharmacological intervention to prevent fractures. Arch Intern Med 164(10):1108-1112. https://doi.org/10.1001/archinte.164.10. 1108

4. Nguyen TV, Center JR, Sambrook PN, Eisman JA (2001) Risk factors for proximal humerus, forearm, and wrist fractures in elderly men and women: the Dubbo Osteoporosis Epidemiology Study. Am J Epidemiol 153(6):587-595

5. Borgström F, Lekander I, Ivergård $M$, Ström O, Svedbom A, Alekna V, Bianchi ML, Clark P, Curiel MD, Dimai HP, Jürisson M, Kallikorm R, Lesnyak O, McCloskey E, Nassonov E, Sanders KM, Silverman S, Tamulaitiene M, Thomas T, Tosteson AN, Jönsson B, Kanis JA (2013) The International Costs and Utilities Related to Osteoporotic Fractures Study (ICUROS)-quality of life during the first 4 months after fracture. Osteoporos Int 24(3):811823. https://doi.org/10.1007/s00198-012-2240-2

6. Kaukonen JP, Karaharju EO, Porras M, Lüthje P, Jakobsson A (1988) Functional recovery after fractures of the distal forearm. Analysis of radiographic and other factors affecting the outcome. Ann Chir Gynaecol 77(1):27-31

7. Morin S, Lix LM, Azimaee M, Metge C, Caetano P, Leslie WD (2011) Mortality rates after incident non-traumatic fractures in older men and women. Osteoporos Int 22(9):2439-2448. https://doi.org/ 10.1007/s00198-010-1480-2

8. Center JR, Nguyen TV, Schneider D, Sambrook PN, Eisman JA (1999) Mortality after all major types of osteoporotic fracture in men and women: an observational study. Lancet 353(9156):878882. https://doi.org/10.1016/s0140-6736(98)09075-8

9. Mallmin H, Ljunghall S, Persson I, Naessén T, Krusemo UB, Bergström R (1993) Fracture of the distal forearm as a forecaster of subsequent hip fracture: a population-based cohort study with 24 years of follow-up. Calcif Tissue Int 52(4):269-272

10. Lauritzen JB, Schwarz P, McNair P, Lund B, Transbøl I (1993) Radial and humeral fractures as predictors of subsequent hip, radial or humeral fractures in women, and their seasonal variation. Osteoporos Int 3(3):133-137

11. Cummings SR, Nevitt MC, Browner WS, Stone K, Fox KM, Ensrud KE, Cauley J, Black D, Vogt TM (1995) Risk factors for hip fracture in white women. Study of Osteoporotic Fractures Research Group. N Engl J Med 332(12):767-773. https://doi.org/ 10.1056/NEJM199503233321202

12. Cuddihy MT, Gabriel SE, Crowson CS, O'Fallon WM, Melton LJ 3rd (1999) Forearm fractures as predictors of subsequent osteoporotic fractures. Osteoporos Int 9(6):469-475

13. Klotzbuecher CM, Ross PD, Landsman PB, Abbott TA 3rd, Berger $M$ (2000) Patients with prior fractures have an increased risk of future fractures: a summary of the literature and statistical synthesis. J Bone Miner Res 15(4):721-739. https://doi.org/10.1359/jbmr. 2000.15.4.721

14. Black DM, Thompson DE, Bauer DC, Ensrud K, Musliner T, Hochberg MC, Nevitt MC, Suryawanshi S, Cummings SR, Fracture Intervention Trial (2000) Fracture risk reduction with alendronate in women with osteoporosis: the Fracture Intervention Trial. FIT Research Group. J Clin Endocrinol Metab 85(11):4118-4124. https://doi.org/10.1210/jcem.85.11.6953

15. Cummings SR, Black DM, Thompson DE, Applegate WB, BarrettConnor E, Musliner TA, Palermo L, Prineas R, Rubin SM, Scott JC, Vogt T, Wallace R, Yates AJ, LaCroix AZ (1998) Effect of alendronate on risk of fracture in women with low bone density but without vertebral fractures: results from the Fracture Intervention Trial. JAMA 280(24):2077-2082 
16. Baron R, Ferrari S, Russell RG (2011) Denosumab and bisphosphonates: different mechanisms of action and effects. Bone 48(4):677-692. https://doi.org/10.1016/j.bone.2010.11.020

17. Zebaze RM, Libanati C, Austin M, Ghasem-Zadeh A, Hanley DA, Zanchetta JR, Thomas T, Boutroy S, Bogado CE, Bilezikian JP, Seeman E (2014) Differing effects of denosumab and alendronate on cortical and trabecular bone. Bone 59:173-179. https://doi.org/ 10.1016/j.bone.2013.11.016

18. Genant HK, Engelke K, Hanley DA, Brown JP, Omizo M, Bone HG, Kivitz AJ, Fuerst T, Wang H, Austin M, Libanati C (2010) Denosumab improves density and strength parameters as measured by QCT of the radius in postmenopausal women with low bone mineral density. Bone 47(1):131-139. https://doi.org/10.1016/j. bone.2010.04.594

19. Ravn P, Weiss SR, Rodriguez-Portales JA, McClung MR, Wasnich RD, Gilchrist NL, Sambrook P, Fogelman I, Krupa D, Yates AJ, Daifotis A, Fuleihan GE (2000) Alendronate in early postmenopausal women: effects on bone mass during long-term treatment and after withdrawal. Alendronate Osteoporosis Prevention Study Group. J Clin Endocrinol Metab 85(4):1492-1497. https://doi.org/ 10.1210/jcem.85.4.6549

20. Neer RM, Arnaud CD, Zanchetta JR, Prince R, Gaich GA, Reginster JY, Hodsman AB, Eriksen EF, Ish-Shalom S, Genant HK, Wang O, Mitlak BH (2001) Effect of parathyroid hormone (1-34) on fractures and bone mineral density in postmenopausal women with osteoporosis. N Engl J Med 344(19):1434-1441. https://doi.org/10.1056/NEJM200105103441904

21. Stroup JS, Rivers SM, Abu-Baker AM, Kane MP (2007) Two-year changes in bone mineral density and $\mathrm{T}$ scores in patients treated at a pharmacist-run teriparatide clinic. Pharmacotherapy 27(6):779788. https://doi.org/10.1592/phco.27.6.779

22. Brown JP, Prince RL, Deal C, Recker RR, Kiel DP, de Gregorio LH, Hadji P, Hofbauer LC, Alvaro-Gracia JM, Wang H, Austin M, Wagman RB, Newmark R, Libanati C, San Martin J, Bone HG (2009) Comparison of the effect of denosumab and alendronate on BMD and biochemical markers of bone turnover in postmenopausal women with low bone mass: a randomized, blinded, phase 3 trial. J Bone Miner Res 24(1):153-161. https://doi.org/10.1359/ jbmr.0809010

23. Kendler DL, Roux C, Benhamou CL, Brown JP, Lillestol M, Siddhanti S, Man HS, San Martin J, Bone HG (2010) Effects of denosumab on bone mineral density and bone turnover in postmenopausal women transitioning from alendronate therapy. J Bone Miner Res 25(1):72-81. https://doi.org/10.1359/jbmr.090716

24. Miller PD, Pannacciulli N, Brown JP, Czerwinski E, Nedergaard BS, Bolognese MA, Malouf J, Bone HG, Reginster JY, Singer A, Wang C, Wagman RB, Cummings SR (2016) Denosumab or zoledronic acid in postmenopausal women with osteoporosis previously treated with oral bisphosphonates. J Clin Endocrinol Metab 101(8): 3163-3170. https://doi.org/10.1210/jc.2016-1801

25. Cummings SR, San Martin J, McClung MR, Siris ES, Eastell R, Reid IR, Delmas P, Zoog HB, Austin M, Wang A, Kutilek S, Adami S, Zanchetta J, Libanati C, Siddhanti S, Christiansen C, FREEDOM Trial (2009) Denosumab for prevention of fractures in postmenopausal women with osteoporosis. N Engl J Med 361(8):756-765. https://doi.org/10.1056/NEJMoa0809493

26. Simon JA, Recknor C, Moffett AH Jr, Adachi JD, Franek E, Lewiecki EM, McClung MR, Mautalen CA, Ragi-Eis S, Nicholson GC, Muschitz C, Nuti R, Torring O, Wang A, Libanati C (2013) Impact of denosumab on the peripheral skeleton of postmenopausal women with osteoporosis: bone density, mass, and strength of the radius, and wrist fracture. Menopause 20(2):130 137. https://doi.org/10.1097/gme.0b013e318267f909

27. Ferrari S, Adachi JD, Lippuner K, Zapalowski C, Miller PD, Reginster JY, Törring O, Kendler DL, Daizadeh NS, Wang A, O'Malley CD, Wagman RB, Libanati C, Lewiecki EM (2015)
Further reductions in nonvertebral fracture rate with long-term denosumab treatment in the FREEDOM open-label extension and influence of hip bone mineral density after 3 years. Osteoporos Int 26(12):2763-2771. https://doi.org/10.1007/s00198-015-3179-x

28. Bone HG, Wagman RB, Brandi ML, Brown JP, Chapurlat R, Cummings SR, Czerwiński E, Fahrleitner-Pammer A, Kendler DL, Lippuner K, Reginster JY, Roux C, Malouf J, Bradley MN, Daizadeh NS, Wang A, Dakin P, Pannacciulli N, Dempster DW, Papapoulos S (2017) 10 years of denosumab treatment in postmenopausal women with osteoporosis: results from the phase 3 randomised FREEDOM trial and open-label extension. Lancet Diabetes Endocrinol 5(7):513-523. https://doi.org/10.1016/ S2213-8587(17)30138-9

29. Bolognese MA, Teglbjaerg CS, Zanchetta JR, Lippuner K, McClung MR, Brandi ML, Høiseth A, Lakatos P, Moffett AH, Lorenc RS, Wang A, Libanati C (2013) Denosumab significantly increases DXA BMD at both trabecular and cortical sites: results from the FREEDOM study. J Clin Densitom 16(2):147-153. https://doi.org/10.1016/j.jocd.2012.02.006

30. Langdahl B, Ferrari S, Dempster DW (2016) Bone modeling and remodeling: potential as therapeutic targets for the treatment of osteoporosis. Ther Adv Musculoskelet Dis 8(6):225-235

31. Siris ES, Adler R, Bilezikian J, Bolognese M, Dawson-Hughes B, Favus MJ, Harris ST, Jan de Beur SM, Khosla S, Lane NE, Lindsay R, Nana AD, Orwoll ES, Saag K, Silverman S, Watts NB (2014) The clinical diagnosis of osteoporosis: a position statement from the National Bone Health Alliance Working Group. Osteoporos Int 25(5):1439-1443

32. Black DM, Cummings SR, Karpf DB, Cauley JA, Thompson DE, Nevitt MC, Bauer DC, Genant HK, Haskell WL, Marcus R, Ott SM, Torner JC, Quandt SA, Reiss TF, Ensrud KE (1996) Randomised trial of effect of alendronate on risk of fracture in women with existing vertebral fractures. Fracture Intervention Trial Research Group. Lancet 348(9041):1535-1541

33. Wells GA, Cranney A, Peterson J, Boucher M, Shea B, Robinson V, Coyle D, Tugwell P (2008) Alendronate for the primary and secondary prevention of osteoporotic fractures in postmenopausal women. Cochrane Database Syst Rev (1):CD001155. https://doi. org/10.1002/14651858.CD001155.pub2

34. Seeman E, Delmas PD, Hanley DA, Sellmeyer D, Cheung AM, Shane E, Kearns A, Thomas T, Boyd SK, Boutroy S, Bogado C, Majumdar S, Fan M, Libanati C, Zanchetta J (2010) Microarchitectural deterioration of cortical and trabecular bone: differing effects of denosumab and alendronate. J Bone Miner Res 25(8): 1886-1894. https://doi.org/10.1002/jbmr.81

35. Black DM, Schwartz AV, Ensrud KE, Cauley JA, Levis S, Quandt SA, Satterfield S, Wallace RB, Bauer DC, Palermo L, Wehren LE, Lombardi A, Santora AC, Cummings SR, Flex Research Group (2006) Effects of continuing or stopping alendronate after 5 years of treatment: the Fracture Intervention Trial Long-term Extension (FLEX): a randomized trial. JAMA 296(24):2927-2938. https:// doi.org/10.1001/jama.296.24.2927

36. Black DM, Reid IR, Cauley JA, Cosman F, Leung PC, Lakatos P, Lippuner K, Cummings SR, Hue TF, Mukhopadhyay A, Tan M, Aftring RP, Eastell R (2015) The effect of 6 versus 9 years of zoledronic acid treatment in osteoporosis: a randomized second extension to the HORIZON-Pivotal Fracture Trial (PFT). J Bone Miner Res 30(5):934-944. https://doi.org/10.1002/jbmr.2442

Publisher's note Springer Nature remains neutral with regard to jurisdictional claims in published maps and institutional affiliations. 